\title{
Morphine : friend or foe?
}

\section{Jane Bates ${ }^{1}$, Liz Gwyther ${ }^{2}$, Natalya Dinat ${ }^{3}$}

1. Ministry of Health, Queen Elizabeth Central Hospital, Blantyre, Malawi

2. Palliative Medicine, University of Cape Town, South Africa

3. Department of Internal Medicine, University of the Witwatersrand, South Africa

Corresponding author: Jane Bates, Queen Elizabeth Central Hospital, Blantyre Email: jbates@malawi.net

\section{Introduction}

\section{'it's a bad drug it can kill and even its side effect(s) are very dangerous.}

This was the comment of an elderly nurse working in the pharmacy of a local Christian Health Association of Malawi (CHAM) facility when asked about oral morphine. Is this what everyone thought? Is this what you think?

A qualitative study has recently been undertaken to investigate the beliefs, attitudes and practises of clinicians, nurses and pharmacy staff in the Southern Region of Malawi towards the use of oral morphine in the palliative care management of HIV/AIDS and cancer. Data was gathered from fifteen interviews with different cadres of health workers from five hospital sites. In this paper we respond to some of the issues raised by those who took part. In so doing we discuss the historical development of morphine availability in Malawi and some of the basic facts about the use of oral morphine in pain management.

\section{Background}

Palliative care has been highlighted as an urgent need for patients with both HIV/AIDS and cancer in sub-Saharan Africa $^{1,2}$. More recently palliative care has been proposed as a basic human right ${ }^{3,4}$. The London declaration on Cancer Control in Africa in 2007 stated that 'African countries will account for over a million cases of cancer per year ${ }^{5}$ with an estimated eighty eight to ninety five percent of patients presenting at a late or end stage of disease. ${ }^{6}$ The mainstay of management for many patients with cancer from the time of diagnosis thus requires a palliative approach with optimal pain and symptom control. Twelve percent of 15-49 year olds in Malawi out of a total population of around thirteen and a half million are infected with HIV, and around sixty one thousand deaths per year are attributable to AIDS. ${ }^{7}$ In HIV pain occurs as a result of a variety of factors: from HIV itself, from opportunistic infections and as a result of the side effects of antiretroviral (ARV) medication. Pain in patients with HIV/AIDS is often underdiagnosed and undertreated ${ }^{8}$. Timely attention to pain and symptom control will help to improve long term adherence for those taking ARVs.

Central to the WHO definition of palliative care is the 'early identification and impeccable assessment and treatment of pain..." Morphine is recommended by the WHO as the drug of choice for severe pain in cancer. Between January and December 2006 fifty one percent of the two hundred and twenty eight patients referred to the adult palliative care service at Queen Elizabeth Central Hospital received oral morphine to control symptoms (either pain or shortness of breath $)^{10}$. The WHO analgesic ladder (page 129), which was initially developed in 1986, has been shown to control pain in over seventy five per cent of patients with cancer ${ }^{11}$. These guidelines have been recommended for pain management in other conditions including HIV/AIDS ${ }^{12}$. The analgesic ladder is part of Ministry of Health management guidelines in Malawi. ${ }^{13}$

\section{What did health workers say about oral morphine? \\ 'it would be important for the medication to be available to all hospitals'}

In Africa advocacy for availability of pain relieving drugs has accelerated under the leadership of the African Palliative Care Association with the backing of several high profile international donors. As part of these advocacy efforts, APCA has hosted a series of regional drug availability workshops across the continent. In June 2006 a high level delegation from Malawi attended the first regional workshop in Entebbe, Uganda, identifying three key areas affecting morphine supply in the country : firstly the poor supply of liquid morphine, secondly, poor data collection and reporting systems by health facilities and thirdly, patients' limited accessibility to morphine.

\section{'sometimes it's there but sometimes it is not available like right now we don't have it'}

In Malawi, morphine is listed as a high priority, vital drug in the Essential Health Package Medicines and Supplies list ${ }^{14}$. Between 1990 and 2007, the International Narcotics Control Board (INCB) received only one annual report on morphine use from Malawi ${ }^{15}$. Following the inclusion of a chapter on palliative care in the Ministry of Health guidelines 'Management of HIV related Diseases' in 2004, morphine (as MST slow release $10 \mathrm{mg}$ tablets) has been supplied free of charge to all hospitals in Malawi which deliver antiretroviral drugs as part of a package of care and support funded through the Global Fund. National supply of MST has been out of stock from 2006 and - due to lack of adequate routine reporting to the INCB - further morphine could not be imported in 2007 as the national import quota ceiling had been reached. Oral morphine solution (an immediate release, short acting preparation of morphine) has also been available through the Lighthouse Trust in Lilongwe for use at a limited number of sites where palliative care teams have developed. Reporting to the INCB has been restarted as of 2007, with the Ministry of Health handing over its responsibility as the national statutory body to the Pharmacy, Medicines and Poisons Board (PMPB). The quota for morphine has recently been increased. Licenses for the purchase and import of morphine are available by application to the PMPB.

It should be available even at their homes, they should be able to take the medicine home or even here at the hospital the process of collecting it should not be too tedious and difficult'

Review of the home based care policy document reveals mention of the need for 'palliative care including psychosocial and spiritual care' but does not specifically emphasise the need for adequate pain relief as part of the package of services for community care ${ }^{16}$. Only step one analgesics (paracetamol, aspirin and diclofenac) of the 
WHO three step analgesic ladder are listed for inclusion in the home based care supervisor's kit. Review of community based services in other African countries also highlights the problem of limited access to oral morphine through home based care programmes ${ }^{10}$. The Uganda model of public health expansion to improve access to morphine has shown that oral morphine can be safely and effectively delivered at community level ${ }^{17}$. Learning from the Ugandan experience (which uses mobile services run by specially qualified nurse prescribers able to assess pain and provide oral morphine liquid where necessary) is critical considering that the vast majority of the population of Malawi live in rural areas, often far away from their nearest health facility.

\section{'the general thinking (is) that probably be is going to become addicted'}

The production, processing and distribution of morphine is carefully controlled and regulated by the INCB in collaboration with national governments in order to minimise the risk of diversion for use by drug addicts. A survey of palliative care users of oral morphine in India found no instances of misuse or diversion of opiates, despite the fears of the authorities ${ }^{18}$. The INCB, the World Health Assembly and other international bodies have noted that, whilst stringent controls are adhered to, the obligation to promote access to opiates for medical purposes is often neglected. Statistics show that developing countries - with eighty percent of the world's population - consume only six percent of the world's supply of morphine ${ }^{19}$.

\section{'I know several workers who are addicted; one is addicted to pethidine and the other valium'}

Poor understanding of the terms addiction, physical dependence and tolerance present barriers to optimal opiate prescribing. Glajchen reports the National Federation of State Medical Boards definition of addiction as 'psychological dependence on the use of substances for their psychic effects, characterised by compulsive use despite harm'20. This is in contrast with physical dependence where gradual reduction of an established opiate dose is required to avoid symptoms of withdrawal which does occur with opiate medication. However this phenomenon is similar to that found with other long term medications such as corticosteroids. In a recent letter to the Lancet, Nigel Sykes from St Christopher's Hospice in London calls for physicians to move on from their 'opiophobic' attitudes ${ }^{21}$. Despite being a frequent concern expressed during our study, none of those interviewed were able to report or recall any actual cases of addiction to support their fears. This is reflected in the literature which reports negligible or no opiate abuse or diversion when opiates are made available for palliative care patients in both African and other settings ${ }^{22-24}$.

'most of my patient(s) when I start morphine I know that the chance of them being addicted is low because some of them are terminal...even if they came addicted when they are about to die it's ok'

'Strong opioids exist to be given, not merely to be withheld; their use should be dictated by therapeutic need and response, not by brevity of prognosis. ${ }^{25}$ At the heart of the WHO definition of palliative care is the stated aim to prevent and relieve suffering by 'the early identification and impeccable assessment of pain and other symptoms...", thus morphine should not be reserved only for 'terminal cases'. Morphine is approximately ten times stronger than codeine and has no ceiling effect. It can be titrated upwards from the initial starting dose as necessary to control symptoms, so long as side effects (predominantly constipation) do not become intolerable.

he (or she) says its only going to work if you give me morphine so next time they come and you give them (an) injection which they think its pethidine they feel good so that is the issue'

Confusion exists between pethidine and oral morphine. In fact pethidine is no longer recommended for the treatment of pain in many settings, whether acute or chronic ${ }^{26}$. This is for a number of reasons, it is short acting, has to be administered intramuscularly (which maybe painful for the patient), and has a less favourable side effect profile than morphine. If used repeatedly metabolites accumulate resulting in a reduction in seizure threshold. A report prepared by the Pain and Policy Studies Group for the APCA Regional Advocacy workshop for Palliative care in Africa mentions that, despite this, pethidine is still widely used ${ }^{13}$.

\section{the main side effect is constipation...so we usually prescribe a laxative as well'}

This is correct, and in Malawi bisacodyl 10mg at night is commonly started concurrently with oral morphine unless the patient has pre-existing diarrhoea. Other side effects include initial drowsiness, particularly in opiate naïve patients, who should be warned of this, but encouraged that it will improve after the first day or two. Starting patients at low doses (for oral morphine liquid $2.5 \mathrm{mg}$ every four hours, for MST tablets $10 \mathrm{mg}$ twice daily) and titrating upwards until pain is controlled also reduces the risk of unnecessary side effects (including respiratory depression). Patients may get a dry mouth and occasionally itching though this is more common when morphine is administered parenterally or via epidural. Nausea and vomiting are rare as side effects in African patients ${ }^{27}$.

\section{Ifeel it would be helpful if you gave us maybe some form of a talk or a course on what type of patients we should prescribe morphine (for). Each clinician here prescribes based on personal judgement'}

The Palliative Care Association of Malawi was registered in 2006. It has been working in partnership with the Ministry of Health to promote, develop and support access to affordable and culturally appropriate palliative care through advocacy, training and technical support. As a result, a five day introductory training course for health care workers has been established. Around five hundred people have completed this training that includes modules on pain assessment, pain management, and the safe and appropriate use of morphine. The national association also arranges clinical attachments so that health professionals who have undergone the course can gain hands on experience in prescribing oral morphine and other medications needed for pain and symptom control.

\section{Summary and conclusions}

According to the WHO analgesic ladder medication should be given 'by mouth, by the clock, and by the ladder' with dose titration upwards until pain is adequately controlled ${ }^{28}$. Effective pain relief has been identified by patients and 
families affected by HIV/AIDS as a main priority to improve their quality of $\operatorname{life}^{10}$, and this priority is central to palliative care. Currently Malawi has limited oncology services, particularly for adults, many of whom present in the late stages of disease.

Physical dependence to long term opiates may occur but this is true of other medications such as antihypertensive medication. Physical dependence should not be confused with the psychological craving which characterizes addiction.

Morphine is naturally occurring and cheap to manufacture. It should be considered as a 'friend' and not a 'foe'. All clinicians, nurses and pharmacy staff in Malawi need to be educated and supported in effective prescription, administration and dispensing of oral morphine in order that - in the words of Dame Cicely Saunders (the founder of the modern hospice palliative care movement) - we 'do all that we can...to help you live until you die'29.

\section{References}

1. Harding R, Higginson I. Palliative care in sub-Saharan Africa. The Lancet 2005; 365:1981-77

2. The untapped potential of palliative care for AIDS. Editorial. The Lancet. 2003; 362:1773

3. Brennan F. Palliative Care as an International Human Right. J Pain symptom Manage 2007. 33(5):494-499

4. The Korea Declaration. Report of the Second Global Summit of National Hospice and Palliative Care Associations, Seoul, March 2005. Available at http://www.worldday.org/documents/Korea_Declaration.doc (cited 2008, July 8)

5. Available from : http://cancer.iaea.org/documents/May2007_London_ Declaration_on_Cancer_Control_in_Africa.pdf (cited 2008, August 8)

6. Pezzatini M, Marino G, Conte S, Catracchia V.Oncology: A forgotten territory in Africa. Annals of Oncology 2007 18(12): 2046-2047. Available from http://annonc.oxfordjournals.org/cgi/content/full/18/12/2046 (cited 2008, July 22)

7. Ministry of Health. ARV guidelines, Malawi. (version 3) 2008

8. Larue F, Fontaine A,Colleau S. Underestimation and undertreatment of pain in HIV disease: multicentre study. British Medical Journal 1997. 314:23. Available from : http://www.bmj.com/cgi/content/full/314/7073/23 (cited 2008, July 22)

9. World Health Organisation. National cancer control programmes : policies and managerial guidelines. Geneva:WHO 2002

10. Bates MJ, Mackriell J, Zijlstra E, Cohen D Integrating HIV palliative care: the Tiyanjane experience. Paper presented at 2nd APCA Palliative Care Conference 19-21st Sept. 2007, Nairobi, Kenya

11. McCaffery M. Pain control. Barriers to the use of available information.
World Health organisation expert committee on cancer pain relief and active supportive care. Cancer; 1992; 1,70 (5 suppl):1438-49

12. World Health Organisation. A community health approach to palliative care for HIV/AIDS and cancer patients in sub-Saharan Africa. Geneva, Switzerland:World Health Organisation; 2004.

13. Ministry of Health. Management of HIV-related diseases. First Edition 2004.

14. Republic of Malawi. A Joint Programme of Work for A Health Sector Wide Approach (SWAp) 2004-2010. Dept of Planning, Ministry of Health Lilongwe

15. Pain and Policy Studies Group. Availability of Morphine and Pethidine in the World, with a special focus on : Africa, Botswana, Ethiopia, Kenya, Malawi, Nigeria, Rwanda, Tanzania and Zambia. University of Wisconsin pain and policy studies group/WHO Collaborating Center for Policy and Communications in Cancer care; Madison, Wisconsin, USA. 2006. (monograph)

16. Ministry of Health. National Community Home Based Care Policy and Guidelines. Ministry of Health. Republic of Malawi 2005

17. Logie D, Harding R. An evaluation of a morphine public health programme for cancer and AIDS pain relief in sub-Saharan Africa. BMC Public Health2005. 5:82. Available at http://www.biomedcentral.com/14712458/5/82, (cited 2006, November 12)

18. Rajagopal M, Joransen D, Gilson A. Medical use, misues and diversion of opioids in India. Lancet 2001. 358 (9276) : 139-143

19. International Narcotics Control Board. Report of the International Narcotics Control Board for 2004. New York, NY:United Nations, 2005. Available from : http://www.incb.org/en/annual_report_2004.html (cited 2008, August 8)

20. Glajchen M. Chronic pain : Treatment barriers and strategies for clinical practise. 2001. JABFP. 2001; 14(3) : 211-218

21. Sykes N. Morphine kills the pain, not the patient. The Lancet. 2007; 369 : 1325-6

22. African Palliative Care Association. Workshop report. Adovcacy workshop for Palliative care in Africa: a focus on essential pain medication accessibility., 2006

23. Porter J, Jick H. Addiction rates in patients treated with narcotics. N Engl J Med 1980; 302:123.

24. Joranson D, Ryan K, Gilson A, Dahl J. Trends in Medical Use and Abuse of Opioid Analgesics. JAMA. 2000; 283(13):1710-1714. Available from : http://jama.ama-assn.org.cgi/content/full/283/13/1710 (cited 2008, August 13)

25. Twycross R, Wilcock A, editors. Palliative Care Formulary Third edition. Alden Group. Oxford 2007.

26. Australian Government. Acute Pain Management : Scientific evidence. Australia and New Zealand College of Anaesthetists and Faculty of Pain Medicine. 2005

27. Merriman A. Palliative Medicine. Pain and symptom control in the cancer and/or AIDS patient in Uganda and other African countries. Fourth Edition 2006

28. Watson M, Lucas C, Hoy A, Back I.,editors. Management of Pain. Chapter 6a. Oxford Handbook of Palliative Care 2005. Oxford University Press, Oxford

29. Available from : http://www.stchristophers.org.uk/page.cfm $/$ link $=540$ (cited 2008, 5 September) 